\title{
REPRESENTANTES DO POVO - UMA MODERNA TEORIA DA REPRESENTAÇÃO NAS VINDICIAE CONTRA TYRANNOS
}

\author{
Frank Viana Carvalho \\ Instituto Federal de Educação, Ciência e \\ Tecnologia de São Paulo - IFSP
}

\begin{abstract}
So impressive, because in the sixteenth century as marked by the increase (some would say 'emergence') of absolutism in Europe, the author of Vindiciae looking bravely show that in all kingdoms and ordered, in both the old and contemporary, the presence of representatives of the people is a constant. In presenting these representatives, some permanent, others extraordinary, what are the intentions of Mornay? This article attempts to show that for the author of Vindiciae, these were the legitimate representatives (the interests) of the people. The examples were intended to establish an important correlation of what happened in other places and times in relation to what the author intended in France sixteenth. Also shows that the king reigned not 'alone', that the power was (or should be) shared with the representatives of the people who had some form of prestige, influence and authority. And finally those who were present the representatives of the people in resistance to tyranny.
\end{abstract}

Keywords: Representation theory, contractualism, theory of resistance, legitimacy.

Resumo: De forma impressionante, já no século XVI, tão marcado pelo aumento (alguns diriam 'surgimento') do absolutismo na Europa, 0 autor das Vindiciae procura corajosamente mostrar que em todos os reinos bem ordenados, tanto nos antigos como nos contemporâneos (quinhentistas), a existência de representantes do povo é uma constante. Ao apresentar esses representantes, alguns permanentes, outros, extraordinários, quais são as intenções de Mornay? Este artigo procura mostrar que, para 0 autor das Vindiciae, esses eram os legítimos representantes (dos interesses) do povo. Os exemplos apresentados visavam estabelecer uma importante correlação do que ocorria em outros lugares e épocas em relação ao que 0 autor pretendia na França quinhentista. De igual forma mostra que o rei não reinava 'sozinho', que o poder era (ou devia ser) compartilhado com esses representantes do povo que detinham alguma forma de prestígio, influência e autoridade. E finalmente apresentar aqueles que seriam os representantes do povo na resistência à tirania. Palavras-Chave: Teoria da representação, contratualismo, teoria da resistência, legitimidade. 
No mundo moderno, sobretudo nas democracias ocidentais, é frequente a discussão sobre o papel dos representantes do povo na composição e atuação nos governos. Para quem se inicia nesta pesquisa, a primeira referência é remeter essas ideias e teorias ao Contrato Social, obra de Jean-Jacques Rousseau, no século XVIII. Entretanto, dois séculos antes, uma obra já tratava do tema de uma maneira muito completa e intrigante.

Vindiciae Contra Tyrannos, ou concernente ao poder legítimo do príncipe sobre o povo e do povo sobre o príncipe ${ }^{1}$ - obra publicada em 1579 e atribuída a Philippe Du Plessis-Mornay ${ }^{2}$, traz a mais detalhada e abrangente concepção da teoria da representação apresentada até o século XVI. Em meio a um período histórico conturbado (Guerras de Religião), as Vindiciae ganharão um destaque especial, e entre os tratados monarcômacos será considerado "de todos, o mais célebre, o mais rigoroso, o mais raciocinado e aquele que teve a maior influência” (JANET, 1971, p. 155) 3 . O tema que perpassa a obra é a teoria contratual, mas este se complementa nos outros tópicos dos quais trata a obra, e dentre eles um dos principais é a teoria da representação.

A teoria contratualista das Vindiciae poderá ser melhor compreendida quando unida à teoria da representação, na forma como esta obra a apresenta e interpreta. Pode parecer surpresa para alguns saber que no século XVI

\footnotetext{
${ }^{1}$ Vindiciae contra Tyrannos, sive de Principis im Populum, Populique im Principem legitima potestate.

${ }_{2}$ Após extensa e exaustiva pesquisa, pode-se hoje concluir que o autor das Vindiciae foi Philippe Du Plessis-Mornay. Ver os tópicos da autoria da obra em "O Pensamento Político Monarcômaco: da limitação do poder real ao contratualismo", tese doutoral de Frank Viana Carvalho, apresentada à Universidade de São Paulo (FFLCH) em março de 2008.

${ }^{3}$ As Vindiciae contra Tyrannos atingem tanta notoriedade entre as publicações do século XVI que diversos eruditos e pesquisadores da teoria política se derramam em elogios a obra de Sthephanus Junius Brutus (pseudônimo do autor): Raymond Gettel (1950), Historia de las ideas políticas, em "seus argumentos se encontra o fundamento de todos os projetos de reformas políticas anteriores à Revolução Francesa". (p. 280); George Sabine (1964), "entre os numerosos trabalhos, todavia, um se destaca acima de todos, as Vindiciae contra Tyrannos". (p. 367); Pierre Mesnard (1936), L'Essor de la Philosophie Politique au XVlème siècle, "expõe a teoria mais enérgica e mais completa das reivindicações constitucionais e dos direitos da consciência". (p. 340); Henri Hauser (1963), "um dos expoentes do século XVl". (p. 46). Jean-Jacques Chevallier (1976), "este trabalho é extremamente significativo e notável (...) tem o mérito de articular inteiramente o político e o religioso." (p. 260); Paul Janet (1971), "perfeitamente suficiente para dar uma ideia de todos os escritos políticos inspirados pela democracia protestante." (p. 158) e Quentin Skinner (2000), As fundações do pensamento político moderno, a "maior e sem dúvida mais célebre contribuição à teoria revolucionária huguenote", a "obra que apresenta o mais completo sumário de todos os principais argumentos desenvolvidos pelos 'monarcômacos' huguenotes na década de 1570". (p. 576).
} 
alguém ousaria defender tão abertamente a representação do povo na defesa de seus direitos. Mas o caráter revolucionário das Vindiciae está ligado não somente ao contexto das Guerras de Religião que assolaram a França, mas também nas múltiplas mudanças ocorridas na Europa desde os descobrimentos marítimos, a Reforma Protestante, o humanismo e o renascimento cultural.

Ao longo de toda a obra, a concepção do papel dos magistrados sempre será objeto de abordagem diversas. Ao analisar a questão dos éforos ou magistrados superiores, o autor mostrará igualmente a identidade dos representantes do povo e o papel que aos éforos é destinado como complemento indispensável dos contratos firmados entre Deus, o rei e o povo e as responsabilidades, direitos e deveres que a eles são reconhecidos nas Vindiciae.

Ao examinar o primeiro contrato exposto nas Vindiciae, conclui-se que o povo tem o direito e o dever de resistir ao rei que, ao afastar-se de Deus, se entrega ao culto de outros deuses, arruinando a Igreja e conduzindo o povo à idolatria. Mas para saber quem pode e deve resistir ao rei, é necessário fazer um exame do problema da representação.

Mas agora vejo qual objeção pode ser feita aqui. 'Qual?', podes perguntar; 'Deve toda uma multidão - quero dizer esse monstro com inúmeras cabeças - lançar-se de cabeça para baixo em fúria raivosa neste problema, como se estivesse em formação de batalha? Qual ordem pode haver em tal multidão, que conselho, que maneira de lidar com as coisas? Quando falamos de todo o povo, queremos dizer aqueles que receberam autoridade do povo - evidentemente os magistrados, que são inferiores ao rei e escolhidos pelo povo, ou constituídos de alguma outra forma eram, por assim dizer, sócios no comando [imperii Consortes] e éforos dos reis, e representam todo o povo reunido [universus populi coetus]. Também queremos dizer que as Assembléias [comitia], não são nada mais que o epítome de cada reino ao qual todos os negócios públicos se referem. (...) setenta anciãos (...) líderes ou príncipes das tribos, um de cada; depois os juizes e prefeitos das cidades individuais - isto é, os capitães de milhares, de centenas, e outros - que presidiram sobre tantas famílias quantas haviam. Por fim, haviam comandantes militares, dignitários e outros, dos quais o concílio reuniu. 
Vimos que foi mais frequentemente proclamado nestes termos: 'E os anciãos se reuniram em Ramá', para a eleição de Saul; 'E todo o Israel se reuniu'; ou 'toda a Judá e Benjamin, etc., quando é improvável que toda a multidão havia se reunido" (Vindiciae, p. 46-47).

É preciso o raciocínio do autor das Vindiciae ao ver na expressão 'todo o Israel' os representantes do povo: os magistrados, os chefes, os governadores, juizes, anciãos, prefeitos, chefes militares e a nobreza. A existência de tais representantes se explica por uma questão pragmática. "Todo o povo é representado pelos oficiais do reino ordinariamente, e pela Assembléia dos Estados extraordinariamente ou anualmente”. (Idem, p. 88). Seria uma retomada do tema tão explorado por François Hotman? Sem dúvida, e agora com uma nova abordagem. Antes, porém, cumpre acompanhar o pensamento deste huguenote para percebermos a clara distinção entre os oficiais do rei e os oficiais do reino, pois nem todos os oficiais existentes no reino podem ser considerados de igual forma a partir da perspectiva do autor das Vindiciae. Aqueles que são indicados pela Assembléia são chamados oficiais do reino ou da coroa, e não do rei. Quanto aos oficiais do rei, é ele que os nomeia e destitui à vontade; os oficiais do reino, ao contrário, recebem sua autoridade do povo, na Assembléia dos Estados $^{4}$, e não podem ser depostos senão pelo povo reunido em Assembléia. Assim, os primeiros dependem do rei, o soberano oficial do reino; os outros, do reino, da soberania do povo, da qual em última instância, o rei e todos seus oficiais e todos os oficiais do reino dependem (Idem, p. 89-90) $)^{5}$.

\footnotetext{
${ }^{4}$ Embora Hotman, em sua obra Franco-Gallia não houvesse citado Assembléias ocorridas no século $\mathrm{XVI}$, talvez em função do tipo de decisões que elas tomaram, as Assembléias dos Estados Gerais de 1560 e 1576 eram acontecimentos recentes na mente dos huguenotes. É verdade que a de 1560 só ocorreu porque a coroa queria 0 apoio deste conselho para buscar uma saída para a grave crise fiscal e constitucional pela qual o reino passava. Mas a de 1576 ocorreu por pressão dos huguenotes, dos politiques e de alguns membros da Liga. (WOLFE, Martin. The Fiscal System of Renaissance Française. New Haven, Con., USA, 1972, p. 121).

5 "São popularmente conhecidos como os oficiais do reino, não do rei. Os oficiais do rei são criados ou dispensados pelo rei à sua vontade; em sua morte, não têm para onde ir e, num certo sentido, são mantidos como mortos. Inversamente, os oficiais do reino recebem a autoridade do povo; na verdade, recebem-na em um conselho público - ou pelo menos estavam acostumados a recebê-la assim em uma época - e não podem ser demitidos, exceto pelos mesmos. Portanto, os primeiros dependem do rei, e os últimos, de um reino; os primeiros, do oficial supremo do reino, que é o próprio rei, e os últimos, do supremo senhorio do povo, do qual o próprio rei deve depender assim como eles. (...)" (Vindiciae, p. 88-89).
} 
Para os oficiais do rei ${ }^{6}$, Mornay utiliza mais de uma vez as expressões 'bajuladores' e 'aduladores'. O autor das Vindiciae, evidenciando sua posição de líder huguenote francês, via nos oficiais do rei a representação máxima do entourage detestado de Charles IX e Henri III. As referências desabonadoras aos 'aduladores' que cercam o rei são abundantes. E com mais razão por se tratar, muitas vezes de elementos que também atuavam de forma eficiente nas lutas contra o partido huguenote, nas ciladas e massacres de que eram vítimas os protestantes. Ainda aqui, o exemplo e alvo típico são os Guise, membros da corte, chefes do grupo católico.

Assim, não se deve confundir oficiais do rei com oficiais do reino. Um exemplo de oficiais do reino são aqueles que servem no Parlamento de Paris - ao contrário de Hotman, Mornay valoriza os oficiais desse Parlamento, dá-lhes autoridade e não os desmerece no exercício do cargo. (Idem, p. 96). Cita também os patrícios ou pais da comunidade, indicados pelas cidades como representantes do povo. Ele faz comparações históricas e os julga superiores ao rei:

Então os oficiais do reino eram superiores ao rei neste reino, quero dizer, o qual não foi instituído por Platão ou Aristóteles, mas pelo próprio Deus, o criador de toda a ordem, e o sumo instituidor de toda monarquia. Estes eram os sete magi ou homens sábios no império Persa; Da mesma forma os ó virtuais na honra monárquica, conhecidos como os olhos e ouvidos do rei, em cujo julgamento, como estudamos, os reis consentiram. Em Esparta havia os éforos, aos quais houve um apelo do rei, e que até mesmo julgaram os próprios reis, como diz Aristóteles. No Egito, os ministros públicos eram costumeiramente eleitos e entregues ao rei pelo povo, pela única razão que não deveriam fazer nada contra as leis. (Vindiciae, p. 93).

Mas não somente nos Estados antigos existiam tais representantes. Ele cita o exemplo da Alemanha, no qual estes cargos são conferidos por eleição,

6 "O rei possui seu grande mestre ou o sumo ecônomo [archioeconomus], seus tesoureiros, caçadores, portadores de escudos, criados e outros, cujos serviços uma vez pareciam depender do rei a tal ponto que quando sua vida acabasse seus ofícios também pareciam estar visivelmente mortos." (Vindiciae, p. 95). 
onde havia príncipes, clérigos, condes, barões, e legados das cidades, cada qual representando a sua comunidade em Assembléias e também em todo o império sempre que houvesse necessidade. De igual forma ele fala da Polônia, ao citar os bispos, palatinos, castelões, nobres e os legados das cidades e das regiões extraordinariamente convocadas. Mornay demora-se no exame daqueles que representam o povo no reino da França, que embora seja considerado por muitos como monarquia hereditária, "não foge à regra geral”. (Idem, p. 93-94). Ao apresentar a França, a lista é estendida:

Porém, todavia o reino francês também possui seus próprios oficiais: o prefeito do palácio, que mais tarde foi intitulado guarda, os marechais, almirantes, chanceler ou chefe referendário, secretários, tesoureiros e outros, que, de fato, em uma época não poderiam ser criados exceto em um conselho público de Três Estados ou clero, nobreza e povo (...) Além do mais, o reino francês possui seus pares do reino como parceiros [consortes] do rei, ou patrícios como pais da comunidade (...) secretário do reino (...) chanceler (...) E existem duques, marqueses, condes, viscondes, barões e castelões; e da mesma forma nas cidades, prefeitos, bailios, cônsules, síndicos, oficiais municipais e outros (...). (Vindiciae, p. 96 e 98).

Além destes, a obra reapresenta os oficiais extraordinários pertencentes à Assembléia dos Três Estados, num tema já explorado por Hotman e Bèze ${ }^{7}$. O interessante é que Mornay, embora não com a mesma ênfase de seus predecessores, argumenta pela manutenção da Assembléia para mostrar que o poder do rei era subordinado e compartilhado com essa esfera administrativa. Além do apelo no poema que fecha as Vindiciae ${ }^{8}$, no texto do tratado há um único pedido explícito e direto para a manutenção efetiva das Assembléias99. Isso é plenamente compreensível, haja vista dois

\footnotetext{
7 "Mas, além disso, havia a Assembléia dos Três Estados [trium ordinum conventus] que numa época se reuniam anualmente, e algum tempo depois no mínimo tantas vezes quanto a necessidade exigisse." (Vindiciae, p. 98). Ao apresentar este assunto, Mornay utiliza muitos dos exemplos utilizados por Hotman na Franco-Gallia e por Bèze no Droit des Magistrats.

${ }^{8}$ No poema final aparece: "Deixes a Assembléia do reino funcionar de acordo com práticas antigas em nome dos Três Estados." (Vindiciae, p. 237).

${ }_{9}^{9}$ Assim fala Mornay sobre o reinado ideal, quando o contrasta com o reino de um tirano: "O reinado pede emprestado a uma constituição equilibrada, a manutenção das Assembléias dos Estados [omnium
} 
importantes fatos: o primeiro é que o apelo de Hotman e Bèze pelas Assembléias dos Estados havia surtido efeito, e o segundo é o fato de que a resistência proposta por Mornay não dependia exclusivamente da ação das Assembléias em reuniões ocasionais, mas da ação permanente dos magistrados. Assim, em seus dias, mesmo com a mudança dos costumes e de alguns aspectos políticos, havia outras instâncias que representavam o povo, às quais o rei devia estar atento para o seu bom reinado. Porém, no aspecto constitucional, ele crê que somente a Assembléia tem autoridade para grandes alterações legislativas, no que diz respeito à eleição ou à lei sálica. Ou seja, nada pode ser mudado "enquanto as leis públicas não tiverem sido revogadas pela autoridade de todo o conselho - isto é, daqueles que representam todo o povo" (Idem, p. 189) ${ }^{10}$.

Qual a intenção do autor das Vindiciae ao apresentar esses representantes, alguns permanentes, outros, extraordinários? São três as intenções de Mornay: primeiramente mostrar que esses eram os legítimos representantes (dos interesses) do povo. Os exemplos apresentados visavam estabelecer uma importante correlação do que ocorria em outros lugares e épocas em relação ao que o autor pretendia na França quinhentista. Em segundo lugar, mostrar que o rei não reinava 'sozinho', que o poder era (ou devia ser) compartilhado com esses representantes do povo que detinham alguma forma de prestígio, influência e autoridade. Em terceiro lugar, ele estava apresentando aqueles que seriam os representantes do povo na resistência à tirania. Mornay sabia que atribuir poderes aos magistrados poderia significar a alguns de seus leitores a diminuição dos poderes do rei, mas ele afirma que não é essa sua intenção: "Não pretendemos que, com este relato, o poder real seja diminuído, ou que os reis sofram como que alguma perda de posição" (Idem, p. 101).

Em todos os reinos bem ordenados, tanto nos antigos como nos contemporâneos de Mornay, a existência de representantes do povo é uma constante. Os títulos, cargos ou nomes variam de época para época, de país para país. Contudo, um fato destaca-se de forma evidente: em todos os países, em todas as épocas é reconhecida à nobreza a qualidade de representante do

ordinum conventus], às quais certos nobres são enviados como delegados para refletir sobre a comunidade." (Vindiciae, p. 180-181).

10 Mornay não desenvolve maiores explicações sobre a lei sálica, apenas confirma o pensamento da época. Ele deixa, contudo, uma abertura indireta para o poder da Assembléia dos Três Estados decidir, se o desejasse, pelo fim dessa lei. 
povo. Dessa forma, no texto das Vindiciae, o autor mostra que, seja em Israel, no Egito, na Pérsia, em Roma, na Alemanha, Polônia ou, sobretudo na França, os membros da nobreza são legítimos oficiais do reino. Sob nomes diversos, em hierarquias distintas, isoladamente ou em conjunto com outras, a nobreza goza do direito de representar o corpo do povo, o universus populus.

Para chegarmos ao ponto principal na investigação da teoria da representação exposta pelo autor das Vindiciae, vamos analisar a função por ele atribuída aos oficiais do reino, legítimos representantes do povo. No contrato que se estabeleceu entre Deus, o rei e o povo como partes solidárias e mutuamente obrigadas, foi estabelecido um pacto com Deus, cuja finalidade era que o povo se tornasse o "povo de Deus". De maneira sucinta, o contrato ${ }^{11}$ nas Vindiciae (que é um duplo contrato) assim se apresenta: o primeiro contrato é uma estipulação (stipulatio), um contrato unilateral, no qual Deus estipula, o povo e o rei prometem. Mas o rei e o povo prometem juntos, contratando assim uma obrigação solidária que 'os obriga' um pelo outro, e um por todos ${ }^{12}$. As duas partes conjuntas são assim estreitamente ligadas no pagamento de sua dívida - ou a execução de sua promessa estando obrigados um pelo outro e um por todos ${ }^{13}$. O segundo contrato (que parte de um ponto de vista estritamente político) é aquele que une o povo ao rei. Para precisar a posição respectiva das partes que condicionam sua participação no contrato, Mornay parte de dois postulados: o povo é

\footnotetext{
${ }^{11}$ Embora não seja objetivo deste artigo analisar a teoria do contrato, e sim a teoria da representação, observe que apresentamos um resumo da teoria contratual nas Vindiciae. Para um aprofundamento no tema recomendamos a leitura da obra de F. Carvalho, "O Pensamento Político Monarcômaco: da limitação do poder real ao contratualismo" (tese), São Paulo: Faculdade de Filosofia, Letras e Ciências Humanas, Universidade de São Paulo, 2008, páginas 126-135 e 165-166.

12 Referindo-se ao povo de Israel, o autor das Vindiciae escreve: "Na investidura de Joás, vimos que houve uma aliança sagrada entre Deus, rei e povo - ou, como afirmado em outros lugares, entre o sumo sacerdote Joiada, todo o povo, e o rei -, no sentido que deveria ele ser o povo de Deus". É interessante perceber que a aprovação popular e divina tinham um significado especial na investidura dos reis, mesmo muito tempo depois do contexto judaico. Kantorowicz (1998) confirma essa aprovação popular e mostra como 0 aspecto religioso tinha peso nesse contexto medieval: "o governo do rei era legalizado exclusivamente por Deus e pelo povo, populo faciente et Deo inspirante." (KANTOROWICZ, 1998, p. 202).

${ }^{13} \mathrm{Como}$, contudo, a estipulação, própria do direito romano pode ser aplicável a um contrato fundado no reino de Israel? Isso não chega a se constituir numa objeção para Mornay: o direito romano era, em efeito, o único no qual as construções jurídicas podiam dar conta desse estado de coisas. A singularidade da estipulação é haver nela a possibilidade da sanção, neste caso, uma punição divina. Sendo o modelo de Israel aplicável a todos os reis e reinos cristãos, ele seria então válido na Europa do século XVI.
} 
superior ao rei e é o verdadeiro soberano do Estado ${ }^{14}$. O primeiro estipulador é o povo, cuja posição já se conhece pelo primeiro postulado sua superioridade lhe dá esse direito. A promessa do rei é direta e simples, mas o povo, por sua vez, não tem a obrigação de se comprometer em resposta à estipulação do rei, a não ser sob uma condição: a promessa de obedecer fielmente ao rei desde que este reine justamente e de acordo com as leis. Se essa condição faltar, o compromisso cai por si mesmo - o povo permanece, de acordo com seu direito, livre de sua promessa ${ }^{15}$.

Ora, na qualidade de devedor solidário, de garantia do contrato que se estabeleceu com Deus, o povo estava obrigado a diligenciar para que o pacto fosse cumprido pronta e integralmente. Se não o fizesse, seria tão relapso e perjuro quanto o rei que deixou de cumpri-lo. Também foi estabelecido um pacto de natureza civil, onde os representantes do povo eram tanto testemunhas e pactuantes solidários, como também partes responsáveis pelo cumprimento das obrigações desse contrato.

Mornay estende o poder do povo aos seus legítimos representantes, os oficiais do reino, entre os quais ele destacou a nobreza (duques, marqueses, condes, viscondes, barões e outros) e os oficiais do Parlamento. Cabe, portanto, a eles o legítimo papel de garantes do contrato formado entre Deus, o rei e o povo. $\mathrm{Na}$ qualidade de representantes do povo, que é parte solidária no contrato, compete-lhes zelar para que o mesmo seja integralmente cumprido. Se não o fizerem serão tão culpados, perjuros e falsos quanto o rei, e tornam-se passíveis do mesmo castigo que sobre ele Deus fará certamente incidir. Por outro lado, os oficiais do reino, além de serem representantes do povo, devem a ele prestar contas. A formulação da ideia de que os oficiais do reino devem ser tomados com "tutores do povo" é feita em várias passagens da obra. $\mathrm{O}$ objeto evidente de Mornay é enfatizar a todos de que tais oficiais têm, não somente o direito como também o dever

\footnotetext{
${ }^{14}$ Ainda do direito romano teremos agora dois contratos de estipulação, cada parte estando, por sua vez, no papel de estipulante e de prometedor. Pareceria, sem dúvida, mais simples de imaginar um contrato 'sinalagmático' (no qual ambos têm o mesmo status e onde as obrigações de uma parte decorreriam automaticamente da reciprocidade entre as partes.), mas não é o que queria Mornay, porque isso colocaria as partes numa posição de igualdade que ele precisamente rejeitava. A adoção da estipulação permitia-lhe, ao contrário, pela sua flexibilidade, chegar ao seu objetivo sem maiores dificuldades.

15 Para Henri Morel (1979), de forma única e evidente no direito romano, o contrato de estipulação permitia tal interpretação, também uma total adequação entre essa construção jurídica e a teoria política das Vindiciae.
} 
irrevogável de proteger o povo, de defendê-lo e guardá-lo. Se não o cumprirem, estarão prevaricando. De forma mais precisa:

Pelo contrário, os nobres devem entender que são chamados para partilhar o fardo bem como a honra, e que a comunidade é seguramente comprometida e confiada ao rei como seu tutor principal e supremo, mas a eles como cotutores. Portanto, assim como tutores - mesmo honorários são transmitidos como observadores da performance da pessoa que principalmente exerce a tutelagem, que eles poderiam exigir regularmente um relato dela e tomar grande cuidado em como ela se comporta; assim os homens de liderança são dados para observar o rei - que julga se estar no lugar do senhor conquanto que este fique nos interesses do guarda - temendo que ele faça qualquer coisa em prejuízo do povo. Da mesma forma, assim como o feito do tutor que está em débito é imputado aos co-tutores, se quando devessem e pudessem fazê-lo, não o colocassem sob suspeita, e também se certificassem de que ele é removido; e como isto é seguramente o caso se não os mantiver informados sobre sua administração, se ele não executar fielmente sua tutelagem ou encargo (Vindiciae, p. 197).

Mornay toma emprestada do Digesto a construção da tutelagem (ou tutoria) quando diz que a comunidade não é entregue aos indivíduos ou a pessoas privadas, mas sim, aos nobres e magistrados, para que ajam como seus tutores. Pois aqueles que não podem se proteger, não são obrigados a proteger. Desta maneira, o povo se coloca sob a tutoria dos magistrados. Eles também são co-tutores do povo junto ao príncipe. Mas o povo não pode se mover contra a tirania de um príncipe - deve esperar o comando de 'todos juntos' (universi), isto é, daqueles que o representam (os magistrados), ou pelo menos de um destes. Mesmo o povo seja de fato o real proprietário (dominus), e o tutor (rei e magistrados) seja apenas mantido na posição de proprietário (pro domino). Assim o povo não pode fazê-lo, exceto por meio daqueles aos quais tenha transferido sua autoridade e poder, sejam eles magistrados inferiores, ou criados extraordinariamente em Assembléia pública.

A premissa básica anteriormente apresentada é de que o povo é uma corporação (universitas), constituída de membros ou homens corporados (universi). Nota-se que o autor das Vindiciae cuidadosamente distinguiu singuli 
de universi em sua explicação sobre a aliança, e excluiu os primeiros de qualquer responsabilidade. De fato, foi o universi que constituiu o príncipe, que é seu principal tutor. O que fica evidente é que o povo ocupa duas funções: ele é co-tutor enquanto representado pelos magistrados e é aquele que necessita da tutoria, enquanto povo. Sendo também enquanto universi, superior ao príncipe, o povo é responsável por este como seu pactuante solidário, e nesta superioridade e responsabilidade é ele que pode autorizar seus representantes para defenderem-no do tirano, caso este seja o rei.

Cabe então, aos oficiais do reino, na qualidade de guardiães e protetores do povo, co-tutores juntamente com o rei, a função de defender o povo, de tudo fazer para a plena realização de bem público (utilitas populi). Se não o fizerem, tornam-se prevaricadores; se dissimularem, deve-se chamálos traidores e desertores, se não defenderem o estado de toda a tirania, devem ser arrolados, eles mesmos, na lista dos tiranos ${ }^{16}$.

Deduz-se do pensamento de Mornay uma ideia de representação de caráter eforal, e de poder do povo atribuído aos representantes e ao rei de forma delegada. Os magistrados são chamados de régulos (reguli $)$, o que na época dos gauleses equivalia à mesma palavra que 'rei'. Os reis, longe de serem absolutos e portadores de autoridade ilimitada, têm seu poder cercado, controlado e fiscalizado pelos representantes do povo, pelos oficiais do reino, magistrados e nobres. Esses oficiais são responsáveis pelo bom cumprimento das finalidades para as quais os reis foram instituídos, isto é, para o bem público, para a felicidade do povo. Estão colocados junto aos reis como 'pequenos reis' (reguli), compartilhando com o rei, considerado apenas como o "primeiro" em todas as honras e encargos do poder. (Vindiciae, p. 89).

Embora pareça um pensamento ainda em formação, pode-se concluir em Mornay que ele revela uma herança do pensamento medieval, onde o soberano era o primeiro entre os iguais - primus inter pares - esta a fórmula usada para designá-los. "Ainda que ele seja como um presidente entre eles, somente está ocupando o primeiro lugar” (Idem). Presidindo a corte dos pares, o bom rei medieval fazia justiça. Como afirma Castro (1960), "é agindo em consonância com os reguli que representam o povo, que o bom

16 "De fato, quanto mais de um perjuro for, mais eles se considerarão obrigados a cumprir seu juramento. Então se fraudam, são advogados traiçoeiros [praevaricatores]; se são coniventes, são desertores e traidores [proditores]; e se não vindicam o país da tirania, são enumerados entre os tiranos. Mas se são certamente patrões, tutores e até mesmo régulos [regull], protegerão e defenderão por todos os meios 0 que se submeteram a proteger." (Vindiciae, p. 198). 
rei de hoje deve gerir os negócios do Estado” (p. 85). Da mesma forma que os soberanos feudais deviam acatar e respeitar os pareceres da corte igualmente soberana, o rei moderno deve cumprir os ditames de seus pares menores, que representam o povo. E quem são esses régulos, éforos e controladores públicos? Quando Mornay a eles se refere, tinha em mente, sobretudo, a nobreza que se fazia representar nas Assembléias dos Estados e os oficiais do reino. A estes cabe a função, a um tempo honrosa e significativa de representar o povo: guardá-lo, protegê-lo, defendê-lo e resistir contra todo e qualquer que agir contrariamente aos seus interesses.

\section{Referências bibliográficas}

BÉZE, T. Du Droit des Magistrats. Genebra: Librairie Droz, 1971.

CASTRO, J. O. R. O contratualismo ideológico das Vindiciae Contra Tyrannos. Belo Horizonte: Universidade de Minas Gerais, tese, 1960.

CARVAlHO, F. V. O Pensamento Político Monarcômaco: da limitação do poder real ao contratualismo", tese doutoral apresentada à Universidade de São Paulo (FFLCH) em março de 2008.

CHEVAlliER, J.- J. As Grandes Obras Políticas de Maquiavel a nossos dias. Rio de Janeiro: Agir Editora, 1976.

GETTEL, R. G. Historia de las ideas políticas. Tomo I. Barcelona: Editorial Labor, 1950.

KANTOROWICZ, E. H. Os dois corpos do rei - um estudo sobre teologia política medieval. São Paulo: Editora Schwarcz, 1998.

HOTMAN, F. Francogallia sive tractatus isagogicus de gegimine Regum Galliae et de jure sucessionis. Genebra, 1573.

. La France-Gaule. (Na coletânea de Simon Goulart). Colônia, em 1578.

JANET, P. Histoire de la Science Politique dans ses rapports avec la Morale. Cinquième Edition, 2 Tomes, Genebra: Skalatine Reprints, 1971.

HAUSER, H. La modernité Du XVI siècle. Paris: Librairie Armand Colin, 1963.

MESNARD, P. L'Essor de la Philosophie Politique au XVIe Siècle. Paris: Boivin \& Cie Editeurs, 1936.

MOREL, H. La Théorie du contrat chez les monarchomaques. Marseille: Presses Universitarires Aix-Marseille, 1979. 
SABINE, G. H. História das Teorias Políticas. Rio de Janeiro: Editora Fundo de Cultura, 1964.

SKINNER, Q. As fundações do pensamento político moderno. São Paulo, Cia. das Letras: 2000.

Email: frankvianacarvalho@hotmail.com

Recebido: janeiro de 2010

Aprovado: junho de 2011 